\title{
SPATIAL DESIGN CONSIDERATIONS FOR UPLIFTING STUDENT'S SOCIETAL PERSONA- A CASE OF UNIVERSITY OF PESHAWAR
} Muhammad Waqas ${ }^{*}$, Syed Akhtar Ali Shah ${ }^{2}$, Aneela Yaseen ${ }^{3}$, Muhammad Jawad ${ }^{4}$, Saima Sarir ${ }^{5}$

${ }^{1 * 3}$ Assistant Professor at Department of Architecture, COMSATS University Islamabad, Pakistan; ${ }^{2}$ Professor Department of Urban \& Regional Planning, University of Peshawar, Pakistan; ${ }^{4,5}$ Lecturer at Department of Rural Sociology, The University of Agriculture Peshawar, Pakistan.

Email: ${ }^{1 *}$ vacas@ comsats.edu.pk, ${ }^{2}$ shahg@ uop.edu.pk, ${ }^{3}$ aneela.yaseen@ @ comsats.edu.pk, ${ }^{4}$ mjawadukhel@aup.edu.pk, 5 drsaimasarir@aup.edu.pk

Article History: Received on $12^{\text {th }}$ June 2021, Revised on $25^{\text {th }}$ June 2021, Published on $29^{\text {th }}$ June 2021

\section{Abstract}

Purpose of the study: This study pursues to find the gap between prudently programmed pure academics in the university and student's societal persona, a result of impulsive learning and informal socializing. This is piloted to justify the need for properly designed informal socializing spaces by comparing actual and proposed spaces at the university campus.

Methodology: A mixed-method strategy is adopted to conduct this research; the theoretical basis is formulated by available literature, and a detailed precedent study is carried out to establish programmatic assumptions in the light of contemporary handling of a similar subject. Visual survey and spatial analysis of building spaces in relationship with human behaviour are performed to analyse preferences of multiple users.

Main Findings: The research culminates in a set of propositions put forth to initiate a purpose-built space that can informally regulate and enhance the social experience in existing academia through spatial design by overall massing of solids and voids, while considering ventilation and thermal comfort through Interconnected Courtyard System, Wind conduits, etc.

Applications of this study: The guidelines are formulated for functional, environmental, and Socio-Psychological aspects to design informal socializing spaces.

Novelty/Originality of this study: Despite learning only from text and oral faculty teachings, the overall milieu of the University through such spaces will add in student's positive personality growth altogether that is ignored in most of the cases.

Keywords: Built Environment Spatial Design, Socio-Psychological Persona, Impulsive Learning, Wind Conduits, Courtyard System.

\section{INTRODUCTION}

The built environment plays a very important role in shaping human behavior (Bell \& Macgregor, 2020; Keralis, Javanmardi, et al., 2020; Shach-Pinsly, 2019). A famous phrase by Winston churchil in 1943, "We shape our buildings and afterward our buildings shape us" (as cited in (Winslow, 2016) reveals the connection of built environment and behavior of the user; this is delineated by Gifford in his book Environmental Psychology, that individual's behavior is changed by the environment and physical settings (Gifford, 2007). The University, similar to other environments where people live together (Chamberlain, Bødker, et al., 2017), offers a mutual living practice (Albeser et al., 2018) and acts both as a learning centre (Ahmed et al., 2017) and a multifaceted social institute (Fromhold et al.). That is to say, the learning environment performs as a communication channel and knowledge is passed on through the spaces (Demirbaș, 1997). Educational institutions, particularly University act as the planning cradle of future generations (Jose, \& Chacko, 2017), and epicentre of urban drifts, must equip itself with all facilities for deliberating various prospects to meet the challenges posed by changing times (Bodolica \& Spraggon, 2021; Fryer, 2017). In the context of urban and regional shifts of ideological, psychological, and physiological boundaries; planning to redesign and restructure future mindsets is extremely crucial. Space as principal canvas plays the role of an educator by default (Kara et al., 2016). The arrangement of spaces guides its inhabitants to perform in ways to respond to society and environments (Kariippanon et al., 2018).

The study focuses on highlighting context-specific processes for the prototype, Student Centre University of Peshawar, abbreviated as SCUoP. The design guidelines, main focus of this paper, is to come up with a set of recommendations that touch upon aspects, i.e., Spatial Program, Physical \& Socio-Psychological Environmental solutions for the proposed complex. In this regard, a model study is carried out for space requirements of the complex, and exploration of methods is undertaken to make the building complex respondent to the existing setup, which could improve overall environment to uplift student's behaviour and societal persona.

Furthermore, this research suggests some design considerations to work out a physical environment to form constructive disposition allowing informal socializing and impulsive learning in a comfortable and pleasing environment. Towards implementing the vision, the study focus is also to workout means that are sensitive towards both built and natural environment. For the purpose solid void placement will be worked out in a manner that could respond to views and ventilation. 


\section{RESEARCH METHODOLOGY}

The entire research procedure is exploratory in nature. Research design is based on qualitative research and categorized into the following phases:

Phase 1. Literature Review

Extensive literature review regarding different concepts and ideas related to education and learning models provided basic exposure to some of the contemporary issues and measures. A theoretical basis for the study is formulated by available literature on the subject, focused group discussions, interviews with students and faculty members of several educational institutions i.e., University of Peshawar, Agricultural University Peshawar, UET Peshawar and COMSATS University Islamabad are conducted.

\section{Phase 2. Assimilation and general study}

Visual surveys and spatial analysis of existing building spaces in relationship with human behaviour are carried out to identify various tiers of social interactions that take place in the University of Peshawar. Pure academic spaces and existing spaces of a chance meeting and impulsive learning are documented to justify the need for Students Centre University of Peshawar (SCUoP). Statistical data is collected from the meteorological department to be aware of accurate weather conditions and consequent design recommendations for thermally comfortable and properly ventilated space design. Moreover, a detailed precedent study is conducted to establish recommendations and programmatic assumptions in the light of contemporary handling of similar subjects.

\section{Phase 3. Recommendations and proposals}

This research proposes a space design that will enhance the student experience for being part of a healthy, socially and psychologically responsive environment. Informal socializing is one of the core forecasts that would subconsciously encourage impulsive learning imparted by deliberate design and relationship of different spaces in the centre. Some of the opportunities offered by the site would thoroughly be taken care of. So that the Centre marks a positive impact on its surroundings and extends a healthier contribution to life in the educational capital of the region. Furthermore, Environmental aspects such as courtyards and wind direction are also taken into consideration to help orient the building/buildings in the existing scenario.

\section{PHASE1. LITERATURE REVIEW}

The Indian Disciple:

Discerning eyes bleed in pain,

For faith is ruined by knowledge in this age.

Teacher Rumi:

Fling it on the body and knowledge becomes a serpent;

Fling it on the heart, and it becomes a friend.

(Bal-e-Jibril-146) Peer-o-Mureed

Poet of the East, Allama Iqbal views Education, as "the highest aim of education should be to strengthen the individuality of all persons so that they may realize their full possibilities/potentialities" (Saiyidain, 1977). For Durkheim education is a 'socialization' of the younger generation, that constitutes the learner's ways of 'seeing, feeling and acting' which he could not have arrived at spontaneously (Walle, 2008). According to (Sumner, 2019) education is the attempt to communicate to the child the values of the group so that he can captivate what conduct is approved and what is disapproved. What should be his behavior and his believes in all kinds of situations as cited in (Gutek, 1994; Bhutto, 2013) in an article, while exploring Constructivist approach towards education writes:

"Constructivists advocate learner center approach and believe that knowledge is constructed, which involve social processes, interaction with the environment, and self-reflection that can be achieved with the help of creating an environment that encourages learner-centered experiences by creating opportunities for learners to; work together, make sense of information for themselves, develop expertise and enhance social interaction for triggering positive impact of socio-cultural factors on one's ability."

Students in educational environments usually have two types of experiences; Formal - identified by educational and organizational codes, the second type is Spatial - growing out of encounters caused by the spatial arrangement of buildings. Space not only reveals the system of education but also has its impact on the spatial configuration of socialization; therefore, the relationship between the conduction of education and social cohesion makes education a process of socialization (Peatross \& Peponis, 1995). 


\section{Functional aspects}

This aspect includes function of spaces, the relationship of spaces with each other and circulation spaces (Wolfgang, 2015). It includes Physical aspects of the environment, architecture, spatial \& furniture arrangements, lighting conditions, temperature, colors even noise and music. Functional aspects affect Human behavior and their moods in spaces where human interaction occurs and is extremely influential in shaping interpersonal relationships (Knapp, 2013). Behavioral responses of users in a space depend upon the spatial arrangements and overall built environment. For instance, socio-petal spaces persuade eye acquaintance and encourage chit chat while socio-fugal spaces have an opposite impact on the overall socialization of users (Hall, 1966; Shepley, 2013).

\section{Socio-Psychological aspects}

The built environment has an impact on the social and behavioral needs of the users (Mehrabian, 1976). SocioPsychological aspects deal with perceptions and psychological needs of the users and also articulate them how to interact within different spaces of the facility. If the spaces are supportive, it will consider behavioral elements, the space will be attractive for students, it will improve work efficiency and as an outcome; quality of education will be improved (Demirbas, 1997; Sanoff, 1993; Rahimi, 2015). Likewise, Rapoport (1990) pinpointed that in addition to physical aspects, a place includes senses and messages that the user perceives based on their experiences and motivations. As cited in (Hansika \& Amarathunga, 2016; Najafi, 2011; Mehrabian 1976) also claimed that an individual's performance depends upon the environment. If the Environment is just prudently program based, it might become boring and avoidance aspects arise (Yunus \& Ernawati, 2018). On the contrary, it becomes inviting if the environment is designed according to the psychological needs of the users (Bangwal \& Tiwari, 2019; Danielsson, 2015; Mehrabian, 1976). Particularly, for an educational environment, it is important to be evaluated in terms of the social context. Since the procreative effects of space not only establishes a background for the pedagogy but also affects overall pedagogical processes (Peatross \& Peponis, 1995)

\section{Phase 2. ASSIMILATION AND GENERAL STUDY}

\section{The University of Peshawar}

It has been almost 70 years since the University of Peshawar was founded, the first public University in KhyberPakhtunkhwa (Ahmad \& Ahmad, 2017). . It offers not only undergraduate and post-graduate programs but also doctoral studies. It is spread over an area of approximately four square kilometers with nearly 14,000 enrolled students. The University has eight research centers within the campus and has its name for its research in medical, social, and natural sciences (UoP, 2021). Like most of the public sector Institutions/Universities, the structure of education in University campus Peshawar can easily be classified into two broad categories i.e., Programmed or Planned Academics and Impulsive Academics.

\section{Spaces for Programmed Academics \& Allied Activities}

Classrooms are the center of these preplanned academic activities, while rest of the activities like Examination, examination Hall, Convocation, Faculty offices, library, laboratories, and different tiers of Administrative units; offices and board rooms, conference and seminar halls, and an auditorium exist to serve the purpose of programmed Education and allied activities. These archetypal sights are detailed in figure $1 \&$ figure 3.
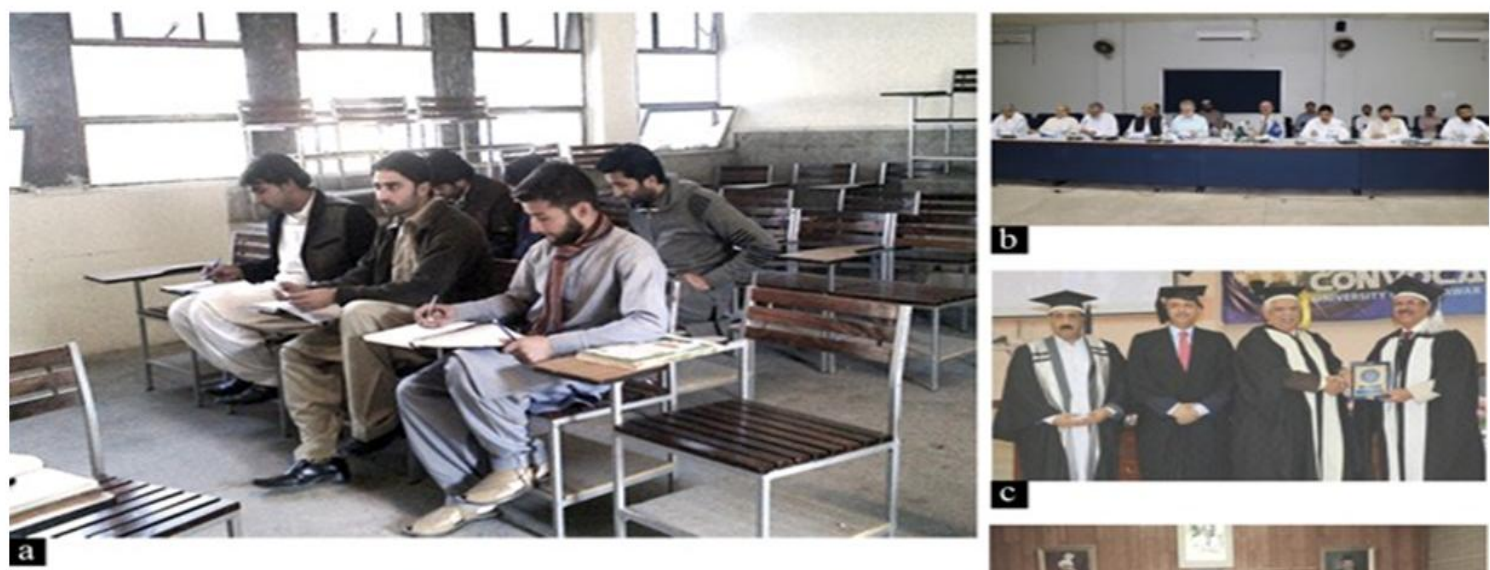

b
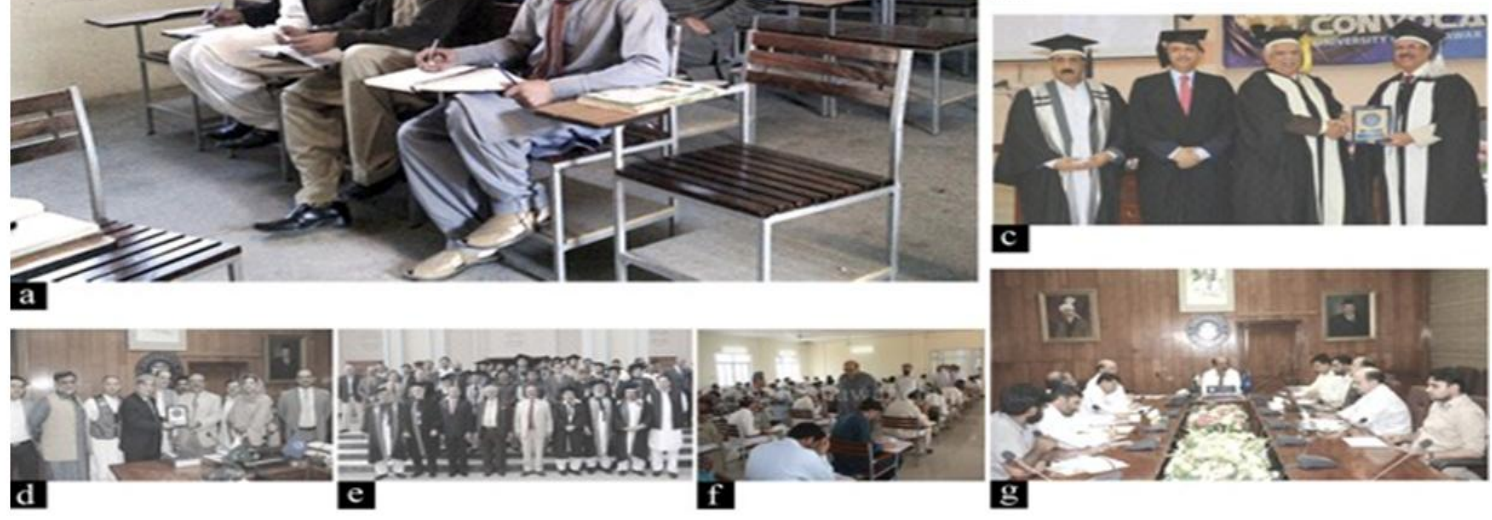

Figure 1: Glimpses of Programmed Academics, which expresses multiple events that are planned beforehand. 
Sources: Snaps (b,c,d,e,g,) www.uop.edu.pk/maingallery/, Snap (f) http://thepeshawar.com/news-and-events/peshawaruniversity-ma-m-sc-exams-2013-after-eidul-azha/
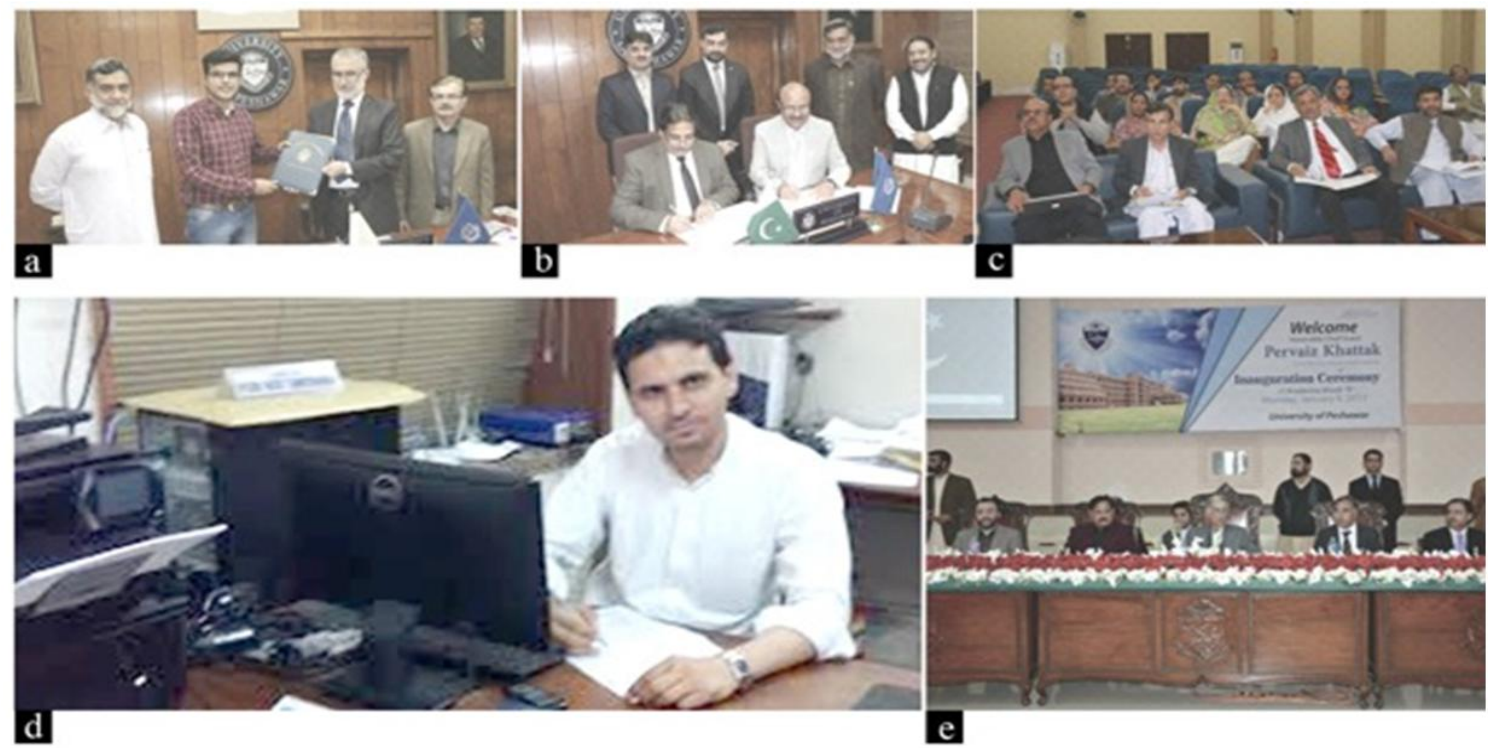

Figure 2: Programmed Academics

Source: Snaps (a,b,c,e) www.uop.edu.pk/maingallery/, Snap(d) http://www.admission.hed.gkp.pk/college.php?col lege_id=3

\section{Existing Spaces for Informal Socializing and Impulsive Academics}

Space contributes extra feature of explicit pedagogy by a chance meeting and encounters, Socialization in a space depends upon the layout patterns. The more dense usage of informal spaces, the more informal chit-chat takes place, and at times subject boundaries are crossed when students from different Departments get a chance to meet (Peatross \& Peponis, 1995). A similar situation is observed during a visual survey of the University campus. For instance, In figure 3a, a set of interactive self-generated actives can be seen; this set of events is an active part of any educational organization. The seemingly random happenings play a very active role in behavior adaptation, social organization, and personality formation/deformation. Figure $3 b$. Expresses a notable phenomenon, where physically challenged learners are waiting for power to turn on the elevators so that they can make it to the upper/lower floors. Locked in the moments, they, however, grab a chance to interact and share. Fig 3c. Students are sharing class notes and are dissecting lecture content in winter's sun. In figure $3 \mathrm{~d}$, a learner is standing alone in the south-facing veranda and balconies that are getting ample amount of winter sun.

Figure 3e is about a typical scene depicting Food entertainment; the environment is a loud story of improper and disorganized spatial configuration. Space, especially in the academic setting, is extremely inadequate to fulfill this very important human need.

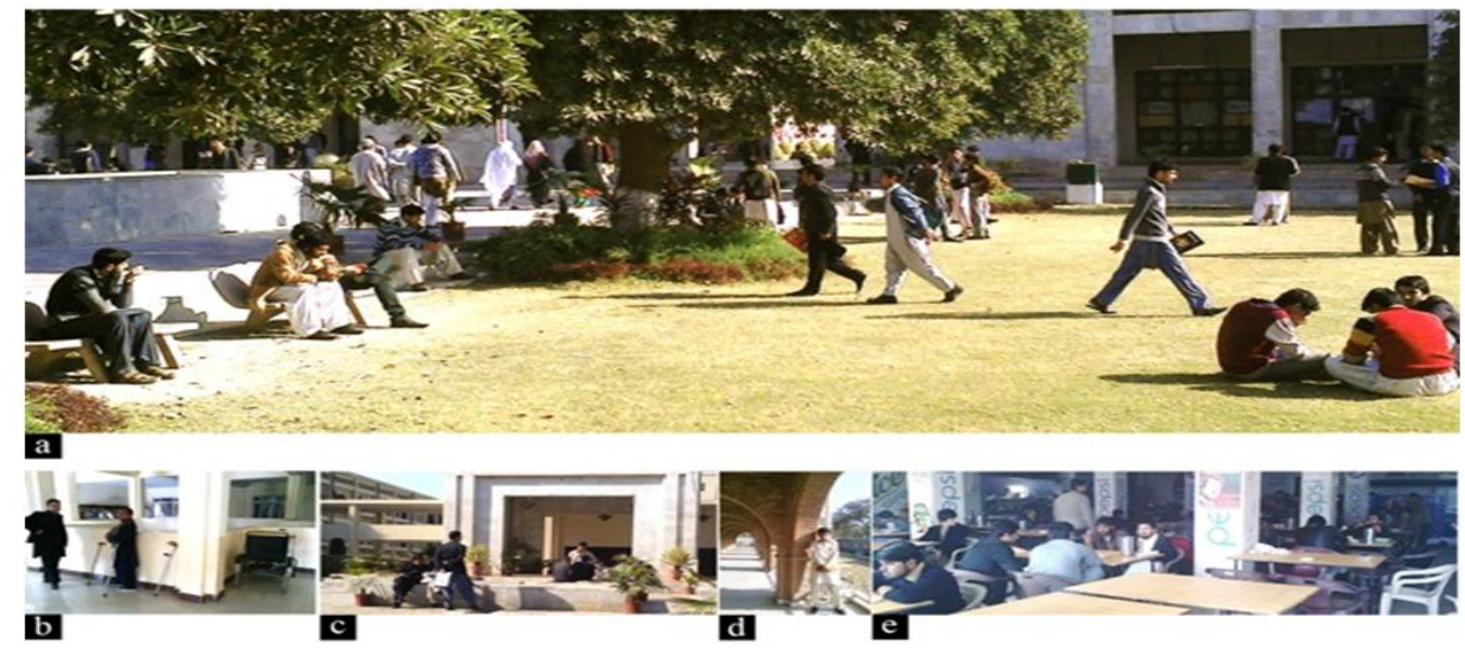

Figure 3: Glimpses of Impulsive social experiences, that take place alongside programmed academics.

Source: Author 


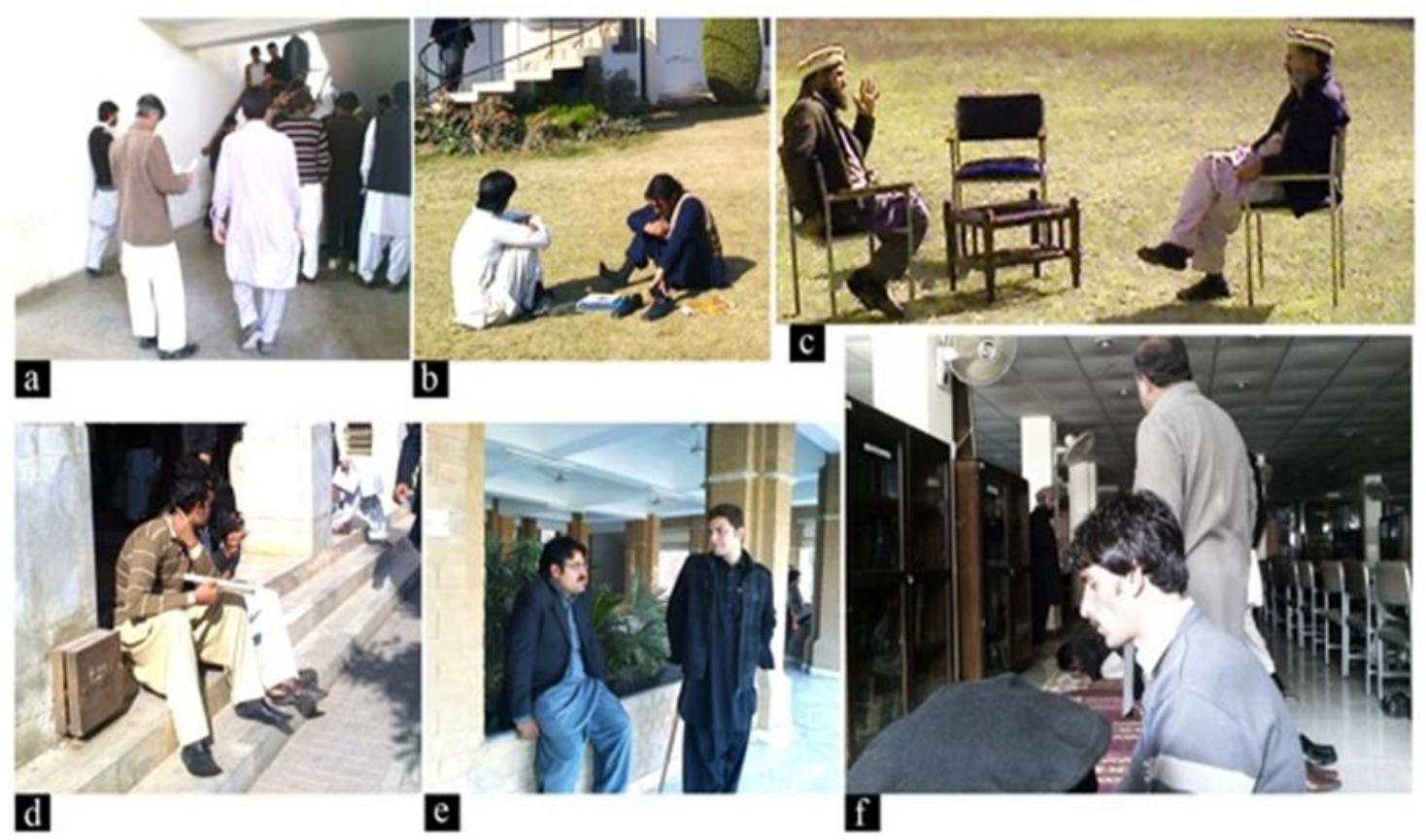

Figure 4: Impulsive social experiences

Source: Author

Figure 4a is a portrayal of Chance meetings; Photocopy summits could randomly spring and get some interesting dimensions while getting a photocopy. Figure $4 \mathrm{~b}$ is more an expression of meditation where apparently the student is focusing hard to understand some academic problem. Figure 4c, Faculty members are enjoying their debate in the soothing sun of January, while in figure $4 \mathrm{~d}$ is an expression of leisure, where students are enjoying transition between two classes. Fig 4e students are peacefully enjoying their free time while on a subconscious level they are observing masses and happenings around them. In figure $4 \mathrm{f}$ congregational prayers are offered in the library area due to either nonavailability or inconvenience of dedicated prayer hall/mosque.

It is established through a visual survey that corridors, circulation spaces, and open lawns in the University campus are spaces of intensive use and are conductors of a chance meeting and informal socializing. Socialization patterns are extended outside pure academic spaces, classrooms, and halls. Where students not only from the same program but also from different faculties get a chance to meet and chit chat. The existing situation fails to offer a dedicated, thermally comfortable, and Spatially Sustained socialization and impulse learning. While let alone the visual survey, the discussion with students not only from the University of Peshawar but also few others in the region pinpointed the need for purpose-built informal socializing spaces as part and parcel of prudently programmed academic spaces.

\section{Precedent Study of Spatial Considerations for Impulsive Academics in Vidyalankar Institute of Technology Mumbai INDIA}

Study of Vidyalankar Institute of Technology designed by Planet 3 Studios Architecture Pvt. Ltd. reveals that apart from Traditional Classrooms and allied spaces, there is a conscious provision of spaces that are created to offer opportunities for a variety of users i.e., Students, Teachers, Parents, Staff, Visitors, and Entrepreneurs to learn from the environment and which could also be used as a platform for informal socializing and impulse learning. These spaces are designed to cater to impulsive activities with flexible inhabitation.

\section{Functional Aspects}

The functional spaces or Design program include: Welcoming Entry, Student Display Space, Art, Music, and Performance Space, Physical Fitness, Casual Eating Areas, Interior and Exterior Vistas, Indoor-Outdoor Connection, Flexible Spaces, Campfire Space, Cave Space, Designing for Multiple Intelligences. Sufficient natural light is provided to the building round the year. This building is almost entirely naturally ventilated. The large openings between individual units ensure that the street benefits from the prevalent southwest wind direction in Mumbai. The cross ventilation of the street happens through the asymmetrically staggered openings on the opposite end. For learners, exposure to the built environment is projected to generate live and impulsive lessons.

\section{Socio-psychological aspects}

The sequence of spaces in figure 5 caters to enhance the sense of neighborhood by carving large punctures that connect inside with the outside; a learning street is designed that acts as a pedestrian extension to the road outside. To encourage students to be communicative, work displays and graffiti boards have been provided. The amphitheater is to create 
opportunities for students' participation in performing arts, theatre, music, poetry, and oratory. The audience can casually sit on the steps or can occupy the entire streets in case of a large number. The sky bridges and passages at different levels can act as balconies from where the performances can be viewed. To indulge in positive physical distractions, students are given opportunities like basketball courts, punching bags, and they can also play table tennis. Apart from a formal canteen, an informal seating opportunity is created along the streets, where not only students but a variety of users can meet, share, talk, and can also eat.

The complex has an open plan; visual connectivity is the most prominent design feature. Learning places, seminar areas, and amphitheater all look out on the street. Outside activities are fused with interiors through alcoves and punctures. By inclusion of outdoor plants inside, individual rooms have a view of both inside and outside. The entire design is based on the concept of multiple uses of spaces. The conference room can be transformed into an exhibition area for displaying students' work. Soft partitions between classrooms can be rearranged to convert it to the seminar hall. The amphitheater can be transformed into a net café and so on.
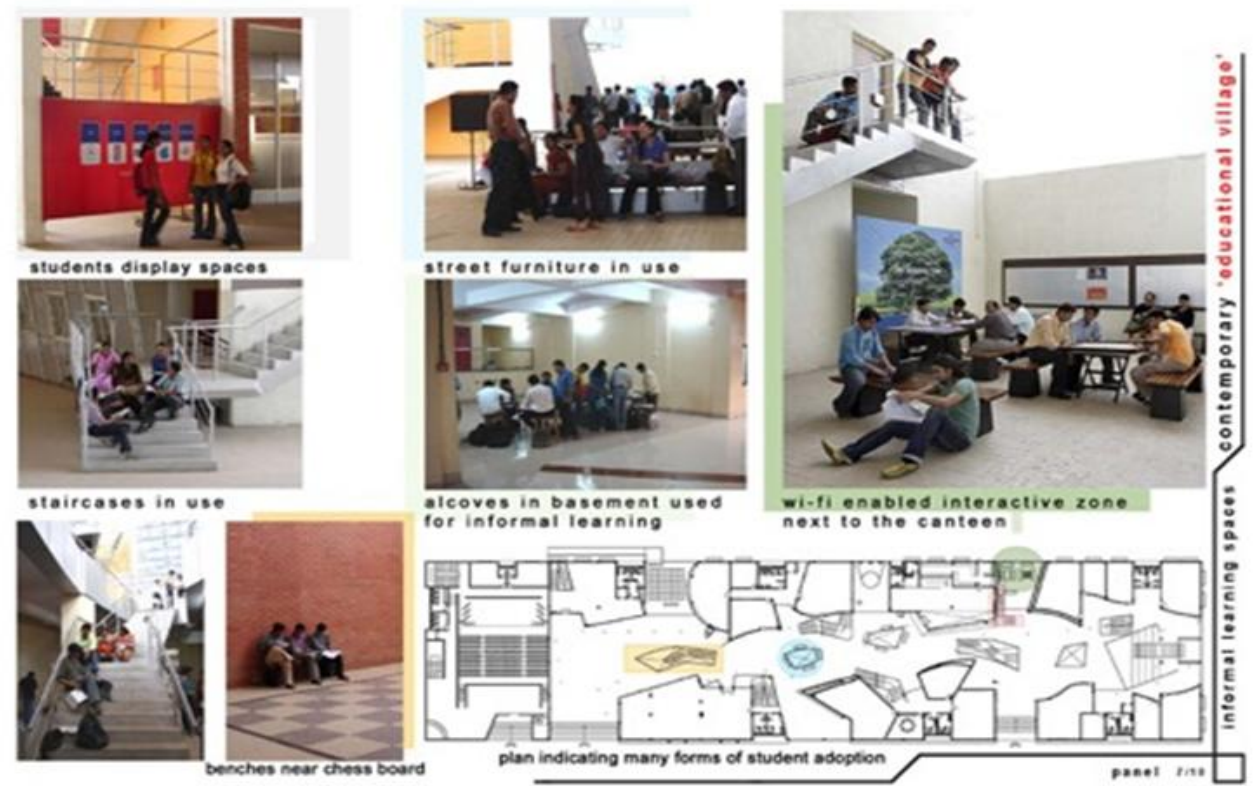

Figure 5: Different impulsive activities and space provisions at Vidyalankar Institute of Technology Mumbai INDIA

Source: (Vidyalankar Institute of technology / Planet 3 Studios Architecture, 2009)

Within the cluster of classrooms, interaction zones and casual seating can potentially be used for campfire sessions. Teachers and students may find these sessions to be more warmly interactive. Nooks, alcoves, and quiet corners on the passages can happen to act like a cave; offering a chance to meditate. The design is fostering different types of intelligence. These include: A man-sized chessboard; for Logical and Mathematical ability, Green vegetation inside; for Nature love and respect, Interaction zones; for Socialization and Nooks \& alcoves; for Self-discovery (Vidyalankar Institute of technology / Planet 3 Studios Architecture, 2009)

\section{DISCUSSION AND RECOMMENDATIONS}

Hans Scharoun in an interview to EM2N explained about his philosophy for the Design for a Primary School in Darmstadt, 1951 that Educational institutions are like urban organisms and act like a place of socialization where user can experience him of herself as part of a community by adding social value in the same spaces. Understanding the spaces as 'social space' transcends the definition of space from the typology of space from school, a building, or even a city (Niggli, (2009))

Following is a set of suggestions and recommendations that could prove to be very effective both in terms of the Spatial Program and Climatic Response for the proposed complex.

\section{Spatial Program}

Socializing spaces not only offer a chance meeting of students from different departments but it also affects the pattern of communication and interaction among students. In universities or educational institutions, students usually experience two types of interactions; one that is programmatically sustained and formal with their instructors or teachers, and the other one is spatially sustained and depends upon the chance meetings and encounters with other students (Peatross \& Peponis, 1995) and at times with teachers as well.

The Spatial Program that is offered at Vidyalankar Institute for enhancing the social experience is further examined and made more relevant to the context of the University campus figure 6. 


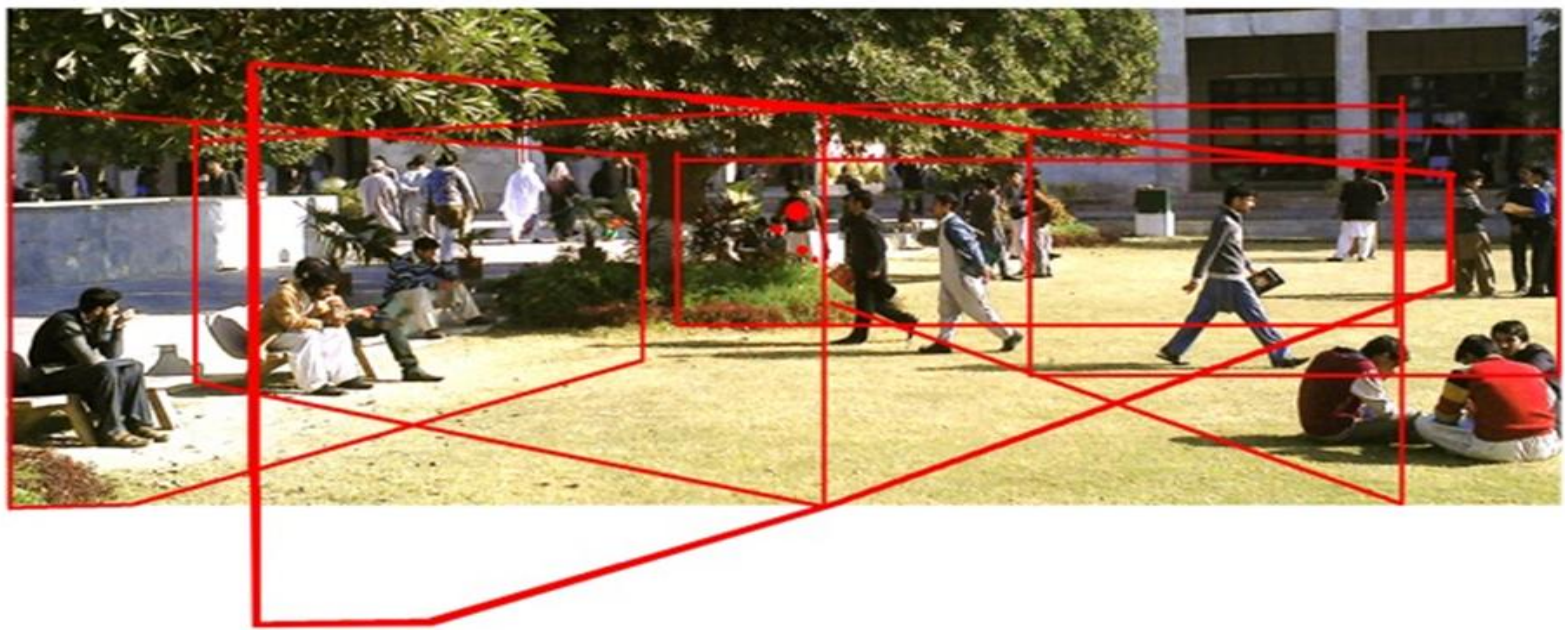

Figure 6: Reflexive live grid to generate Impulsive sets of Spatial arrangements

\section{Source: Author}

After some of the cultural variations and environmental aspects following sets of activities could be considered while working out a detailed program for the Student's Centre:

Welcoming Entrance Lobby, Student Display Space/s, Art, Music, Debate, Performance area/s, Physical Fitness, Casual Eating Areas, Interior and Exterior Vistas with informal catch-up areas, Campfire Space, Cave/meditation Space, Praying area, Career Counseling, General Counseling, Film/Drama zone, Gaming alley, etc. These facilities will always welcome informal activities and may tempt spontaneous participation to generate a healthy outcome figure 7 . It accentuates informal socialization.

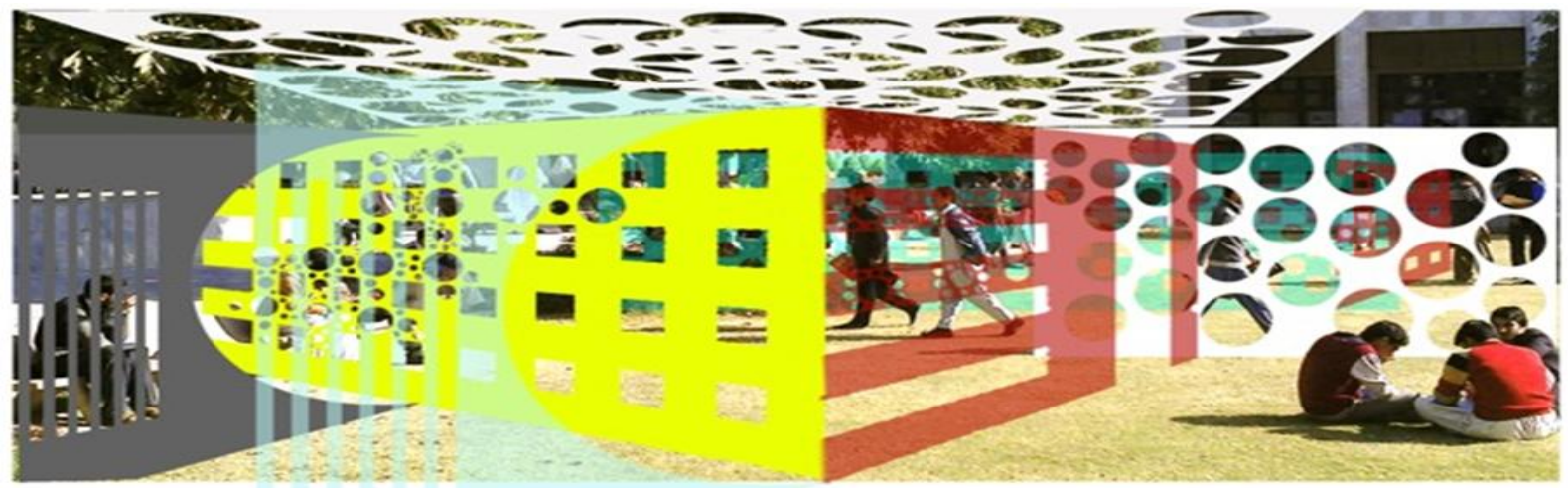

Figure 7: An imaginary rendition of informal open zones, based on the live grid, responding to Impulsive occurrences

Source: Author

\section{Design Features}

Transparency is very important in terms of material selection and its use. This would provide the centre a sense of builtin surveillance. Other features to be incorporated are: Indoor-Outdoor connectivity, Flexibility among spaces, and Adaptability for multiuse of spaces

\section{Environmental Consideration}

\section{Interconnected Courtyard System}

"Natural light with cast shadows, fluctuations and color rendition is the yardstick by which humans assess light quality, and is in part related to cultural background, climate and location. Personal experience also plays a role. People are influenced by the prevailing light condition (Mueller, 2003). According to Reynolds (J.S.Reynolds, 2003), in a courtyard-type neighbourhood, $25 \%$ of the site must be left open to the sky, either in one chunk or in piecemeals to cater for light and air.

A range of $25-40 \%$ is recommended for the environment-sensitive configuration of solids and voids. Solids and voids should be juxtaposed in a way that serves at least three purposes, i.e., light, ventilation, views, and vistas, by permeating 
the landscape in geometric solids. Figure 8 is a model sketch based on this system. Recommended courtyard/s orientation is southwards for improved building performance in both summers and winters.

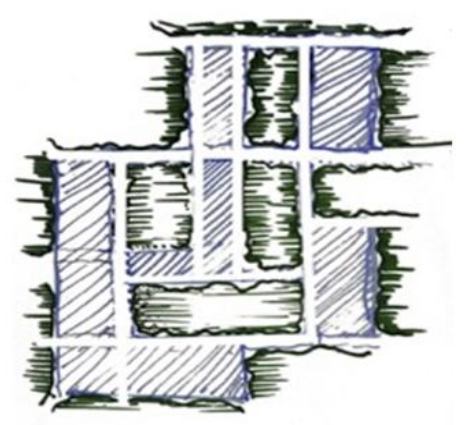

Figure 8: Sketch expressing the time-tested mechanism to handle masses of solids and voids

Source: Author

\section{Natural Ventilation}

Figure 9 represents the wind Analysis explaining and Percentage from various directions in the given months.

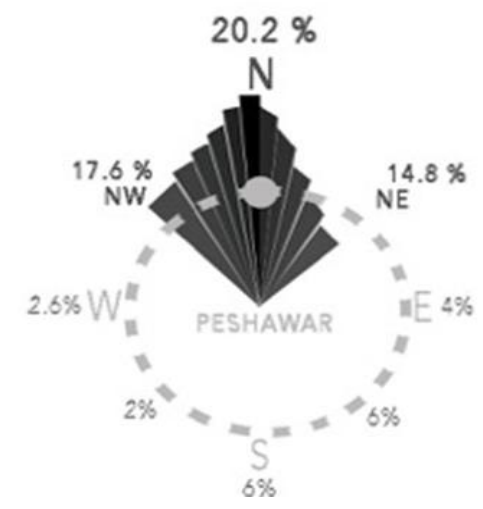

Figure 9: Wind Analysis explaining Wind Percentage from various directions in the given months

Source: Author

The table in Figure 10 is a compilation of 30 years of data by the Meteorology department published in 2004 by the Federal Bureau of Statistics Government of Pakistan (Federal Bureau of Statistics Government of Pakistan, (2004)).

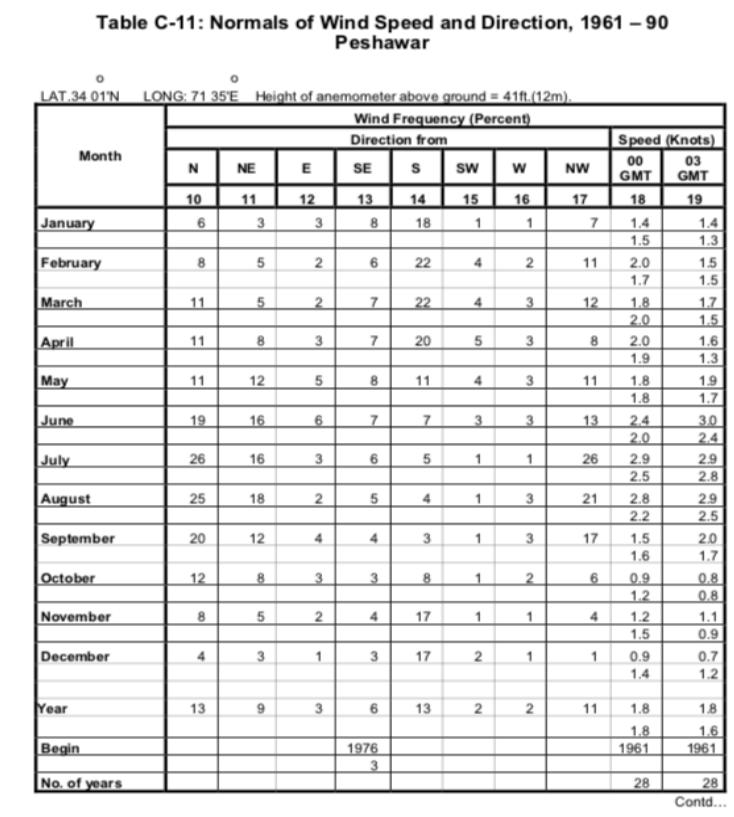

Figure 10: Windspeed and direction at Peshawar, P.283

Source: Pakistan Meteorological Department-Federal Bureau of Statistics 2004 Government of Pakistan 
The detailed monthly analysis for Peshawar is concluded in Figure 11 for the months of May, June, July, August and September. During this period of summer outside the wind is desired the most in Peshawar.

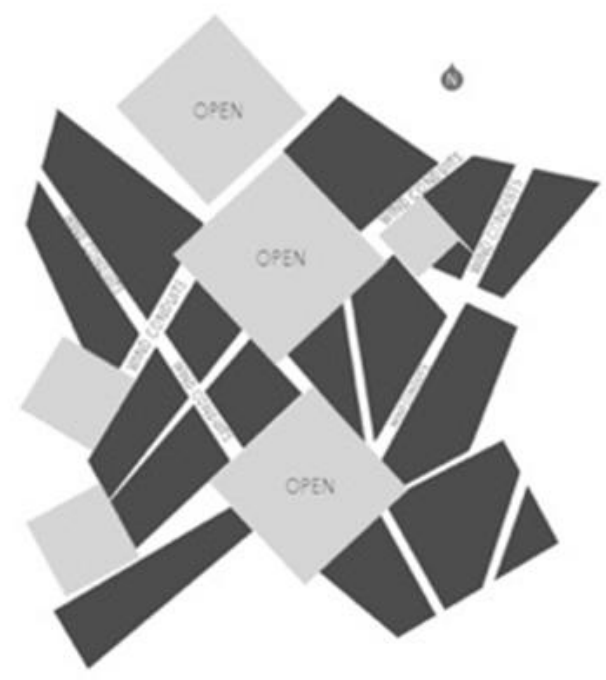

Figure 11: Idea of Intermingling Solids \& Voids, while catering the Wind Orientation in Peshawar

Source: Author

Wind Direction in Peshawar: Throughout the summer season for the aforementioned months, the temperature remains warm normally, the environment is calm $26.2 \%$ of the time, $20.2 \%$ wind comes from the Northside while $17.6 \%$ from the North West and $14.8 \%$ of the wind comes from North Eastside. $52.6 \%$ wind flows from three directions North East, North, and North West; outlining $90^{\circ}$. The Remaining $20.6 \%$ of the wind comes from various directions covering $270^{\circ}$.

Wind Conduits: From the environmental viewpoint, buildings account for nearly half of all energy consumption and raw material used around the globe (Varma, 2014). The diagram in figure 7 is a clue to not only break down the building Masses to place interconnected courtyard system according to recommended ratio but is also an estimated response to the prevailing wind direction of Peshawar. Conduits are carved in the direction of the prevailing Summer Wind, which will make the complex airy and will also connect different zones of the complex. The complex will be windy for $50 \%$ of the time, which will not only limit the energy demand of building blocks but also will constantly aerate the complex to cater to the unwanted odour that could otherwise be created due to constricted spaces.

\section{CONCLUSION}

During student training years, pure academics are prudently programmed while the student social, creative, and diagnostic compelling personae; is propelled with less and in certain circumstances inconsiderate intensity. These are the areas where contemporary education models are focusing on developing critical thinking to uplift the overall state of society. To answer this subject, some of the activities are recommended under the heading Spatial Program. These activities will help accentuate the overall social experience.

Any space is bestowed with natural gifts, in the form of a physical environment; the Students' Centre will be an initiative in the public sector education campuses towards realizing environment-sensitive, social architecture. Classic mechanisms are revisited for achieving better results in terms of environment responsive geometric configurations. The use of prevalent natural opportunities, visual permeability, and aerating corridors are some of the design features that would make the prospective building complex respondent to the existing setup. For environmental concerns, the future Students' Center has to be oriented North-South with a web of interconnected courtyard systems. For catering summer wind factor, wind conduits are to be carefully designed within a band of angles in between 90 degrees from Northeast to Northwest. This will be a passive design provision to cater for more than 50 percent of the Summer Wind in Peshawar.

These recommendations and suggestions will pave a pathway for Concept Morphing of context-sensitive architectural evolution in the form of Students' Centre University of Peshawar (SCUoP) figure 12.

SCUoP is to create a pleasant example of Socio-Psychological space design that will enhance the student experience for being part of a healthy and socially responsive environment. Informal socializing is one of the core forecasts that would subconsciously encourage impulsive learning imparted by deliberate design of activities and relationships of different spaces in the center. Some of the environmental opportunities offered by the site are thoroughly taken into consideration so that the Centre marks a positive impact on its surroundings and extends a healthier contribution to life in the educational capital of the region. 


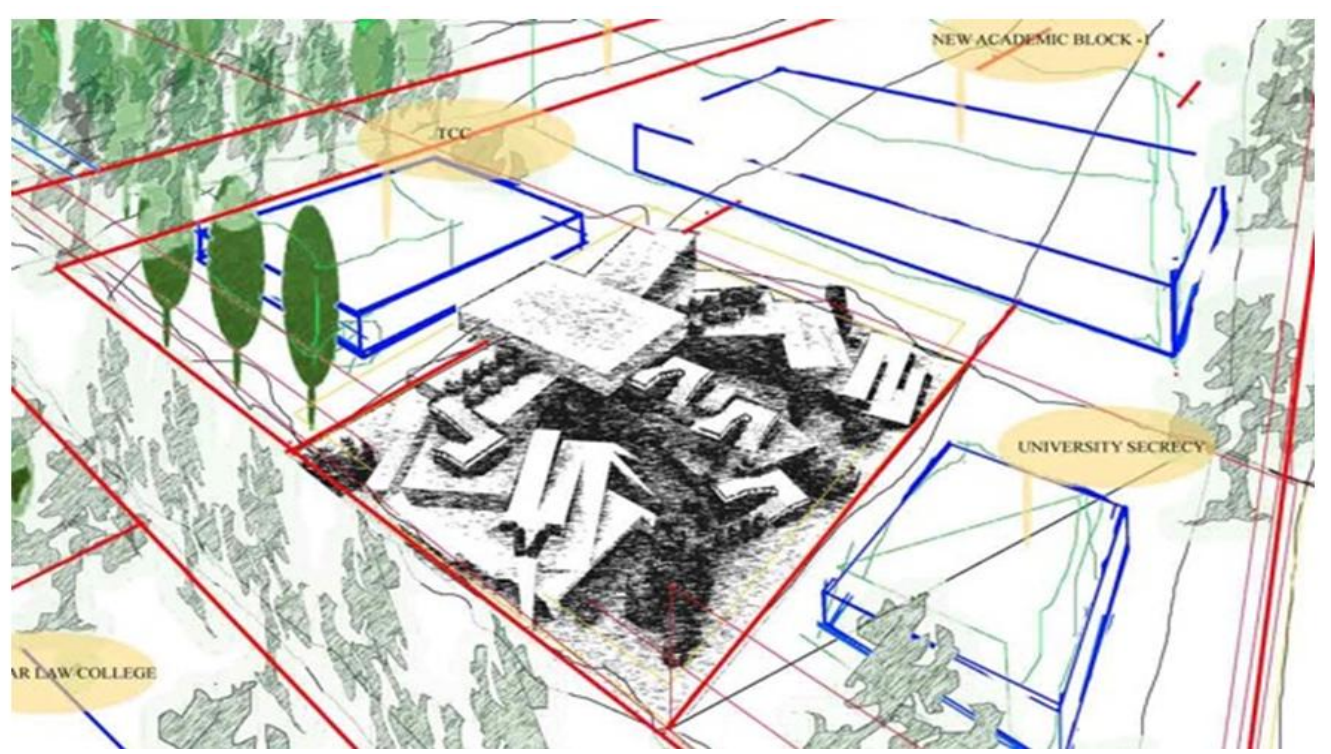

Figure 12: Fictional View; Concept Morphing of the Future's Students' Center

Source: Author

\section{LIMITATION AND STUDY FORWARD}

Further research is to be carried out to establish a framework for the number of inhabitants and space sizes. Also, the daylighting factor can be further explored to improve the building's performance.

\section{ACKNOWLEDGEMENT}

Peshawar University administration for the cooperation to conduct our visual surveys throughout University Campus. The University of Agriculture Peshawar is specially mentioned in this regard.

COMSATS University Islamabad's administration for the motivation and creating a conducive environment to carry out this study.

Mr. Alamgeer Khan (Lecturer Rural Sociology AUP), for his unwavering support and guidance. He is a gem of a person.

\section{AUTHORS CONTRIBUTION}

Dr. Syed Akhtar Ali Shah: His significant contribution is to structure and focus the study.

Aneela Yaseen: Literature review and developing the method.

Dr. Muhammad Jawad: Referencing and outreach.

Dr. Saima Sarir: Proofreading and research designing.

\section{REFERENCES}

1. Ableser, J., \& Moore, C. (2018). The Role of the Teaching and Learning Center in Promoting Transformative Learning at a Metropolitan University. Metropolitan Universities, 29(3), 53-72. https://doi.org/10.18 $\underline{060 / 21456}$

2. Ahmad, A., Sulan, N., \& Rani, A. A. (2017). Integration of learning organization ideas and Islamic core values principle at University. The Learning Organization. https://doi.org/10.1108/TLO-05-2017-0051

3. Ahmad, S., \& Ahmad, S. (2017). Status of ICT in the University Libraries of Khyber Pakhtunkhwa. Pakistan Library \& Information Science Journal, 48(2).

4. Bangwal, D., \& Tiwari, P. (2019). Workplace environment, employee satisfaction and intent to stay. International Journal of Contemporary Hospitality Management. https://doi.org/10.1108/IJCHM-04-2017$\underline{0230}$

5. Bell, M., \& MacGregor, C. (2020). Models of behaviour change relating to energy and the built environment: An analytical review. BRANZ Study Report SR439. Judgeford, New Zealand: BRANZ Ltd.

6. Bhutto, S., \& Chhapra, I. U. (2013). Educational Research on "Constructivism"-An Exploratory View. International journal of scientific and research publications, 3(12), 1-7.

7. Bodolica, V., \& Spraggon, M. (2021). Incubating innovation in university settings: building entrepreneurial mindsets in the future generation of innovative emerging market leaders. Education+ Training. https://doi.org/10.1108/ET-06-2020-0145 
8. Chamberlain, A., Bødker, M., Hazzard, A., McGookin, D., De Roure, D., Willcox, P., \& Papangelis, K. (2017). Audio technology and mobile human computer interaction: From space and place, to social media, music, composition and creation. International Journal of Mobile Human Computer Interaction (IJMHCI), 9(4), 25-40. https://doi.org/10.4018/IJMHCI.2017100103

9. Danielsson, C. B. (2015). Aesthetics versus function in office architecture: employees' perception of the workplace. NA, 27(2).

10. Demirbaş, Ö. O. (1997). Design studio as a life space in architectural education: Privacy requirements (Doctoral dissertation, Bilkent University).

11. Federal Bureau of Statistic Government of Pakistan (2004). Compendium on Environment Statistics of Pakistan.

12. Fromhold-Eisebith, M., \& Werker, C. (2013). Universities' functions in knowledge transfer: a geographical perspective. The Annals of regional science, 51(3), 621-643. https://doi.org/10.1007/s00168-013-0559-z

13. Fryer, L. K. (2017). Building bridges: Seeking structure and direction for higher education motivated learning strategy models. Educational Psychology Review, 29(2), 325-344. https://doi.org/10.1007/s10648-017-9405-7

14. Gifford, R. (2007). Environmental psychology: Principles and practice (p. 372). Colville, WA: Optimal books.

15. Gutek, G. L. (1994). A history of the western educational experience. Waveland Press.

16. Hall, E. T. (1966). The hidden dimension (Vol. 609). Garden City, NY: Doubleday.

17. Hansika, W., \& Amarathunga, P. (2016). Impact of Office Design on Employees' Productivity; A Case Study of Banking Organizations of North Western Province in Sri Lanka. University of Sri Jayewardenepura, Sri Lanka, 13th international conference on business management (ICBM). https://doi.org/10.2139/ssrn.2910255

18. Jose, S., \& Chacko, J. (2017). Building a sustainable higher education sector in the UAE. International Journal of Educational Management. https://doi.org/10.1108/IJEM-05-2016-0102

19. Kara, A. M., Tanui, E., \& Kalai, J. M. (2016). Educational service quality and students' satisfaction in public universities in Kenya.

20. Kariippanon, K. E., Cliff, D. P., Lancaster, S. L., Okely, A. D., \& Parrish, A.-M. (2018). Perceived interplay between flexible learning spaces and teaching, learning and student wellbeing. Learning Environments Research, 21(3), 301-320. https://doi.org/10.1007/s10984-017-9254-9

21. Keralis, J. M., Javanmardi, M., Khanna, S., Dwivedi, P., Huang, D., Tasdizen, T., \& Nguyen, Q. C. (2020). Health and the built environment in United States cities: measuring associations using Google Street Viewderived indicators of the built environment. BMC public health, 20(1), 215. https://doi.org/10.1186/s12889020-8300-1

22. Knapp, M. L., Hall, J. A., \& Horgan, T. G. (2013). Nonverbal communication in human interaction. Cengage Learning.

23. Lawrence, D. L., \& Low, S. M. (1990). The built environment and spatial form. Annual review of anthropology, 453-505. https://doi.org/10.1146/annurev.an.19.100190.002321

24. MacCannell, D. (1976). Public Places and Private Spaces: The Psychology of Work, Play, and Living Environments. https://doi.org/10.1086/226666

25. Mueller, Helmut FO, and Heide G. Schuster (2003). Utilizing Daylight. In: In detail Solar ArchitectureStrategies, Vision, Concepts, edited by Christian Schittich. Birkhauser, Basel, Switzerland.

26. Najafi, M., \& Shariff, M. K. B. M. (2011). The concept of place and sense of place in architectural studies. International Journal of Human and Social Sciences, 6(3), 187-193.

27. Niggli, Mathias Müller and Daniel (2009). Building as city, city as building. http://www.em2n.ch/press/i nterviews/howwebecamewhowearepart1

28. Peatross, F. D., \& Peponis, J. (1995). Space, education, and socialization. Journal of Architectural and Planning Research, 366-385. Publisher name is missing

29. Preiser, W. F., White, E., \& Rabinowitz, H. (2015). Post-Occupancy Evaluation (Routledge Revivals). Routledge. https://doi.org/10.4324/9781315713519

30. Rahimi, S. (2015). Social interaction in student residence halls: An architectural perspective.

31. Rapoport, A. (1990). The meaning of the built environment: A nonverbal communication approach. University of Arizona Press.

32. Saiyidain, K.G. (1977) Iqbal's Educational Philosophy. Sh. Muhammad Ashraf Kashmiri Bazaar, Lahore .

33. Sanoff, H. (1993). Designing a responsive school environment. Children's Environments, 140-153.

34. Shach-Pinsly, D. (2019). Measuring security in the built environment: Evaluating urban vulnerability in a human-scale urban form. Landscape and urban planning, 191, 103412. https://doi.org/10.1016/j.lan durbplan.2018.08.022

35. Shepley, M. M., Pasha, S., Ferguson, P., Huffcut, J. C., Kiyokawa, G., \& Martere, J. (2013). Design research and behavioral health facilities. The Center for Health Design.

36. Sumner, W. G. (2019). Folkways: A study of the sociological importance of usages, manners, customs, mores, and morals. Good Press.

37. Van de Walle, G. (2008). Durkheim and socialization. Durkheimian studies, 14(1), 35-58. https://doi.org/10. 3167/ds.2008.140105 
38. Varma, K., Chaurasia, M., Shukla, P., \& Ahmed, T. (2014). Green building architecture: a literature review on designing techniques. International Journal of Scientific and Research Publications, 583.

39. Vidyalankar Institute of technology / Planet 3 Studios Architecture (2009). https://www.archdaily.com/1593 6/vidyalankar-institute-of-technology-planet-3-studios-architecture\#

40. Watson, D. (2003). Time-saver standards for urban design. McGraw-Hill Education.

41. Winslow, D. (2016). We Shape Our Buildings and Afterwards Our Buildings Shape Us' Interpreting Architectural Evolution in a Sinhalese Village. Alternative Pathways to Complexity: A Collection of Essays on Architecture, Economics, Power, and Cross-Cultural Analysis, 239-258. https://doi.org/10.5876/97 $\underline{81607325338 . c 011}$

42. Yunus, E. N., \& Ernawati, E. (2018). Productivity paradox? The impact of office redesign on employee productivity. International Journal of Productivity and Performance Management. https://doi.org/10.110 $\underline{\text { 8/IJPPM-12-2017-0350 }}$ 